\title{
On the effects of the reunification on German researchers' publication patterns
}

\author{
Antoine Archambault ${ }^{*}$, Philippe Mongeon ${ }^{1}$, and Vincent Larivière ${ }^{1,2}$ \\ ${ }^{1}$ École de bibliothéconomie et des sciences de l'information, Université de Montréal, Montréal, QC, Canada. \\ ${ }^{2}$ Observatoire des Sciences et des Technologies, Centre Interuniversitaire de Recherche sur la Science et la \\ Technologie, Université du Québec à Montréal, Montréal, QC, Canada.
}

*Correspondence to: antoine.archambault@umontreal.ca

\begin{abstract}
After developing independently following World War II, the research systems of East and West Germany reunited at the end of the Cold War, resulting in Westernization of East German Research institutions. Using data from the Web of Science over the 1980-2000 period, this paper analyses the effects of these political changes on the research activity of scholars from East and West Germany before and after the reunification. It shows that these groups differ in terms of levels of production, publication language, collaboration patterns and scientific impact and that, unsurprisingly, the scholarly output of the East became much more similar to that of the West after the reunification. At the level of individual researchers, analysis shows that East German researchers who had direct or indirect ties with the West prior to the 1990s were less affected by the reunification, or were perhaps quicker to adapt to this major change, than their colleagues who were more deeply rooted in the Eastern research system.
\end{abstract}

\section{Introduction}

In October 1990, the German Democratic Republic (GDR) and the Federal Republic of Germany (FRG) reunited into a single country. This reunification first affected the two German entities politically and then quickly had repercussions on other spheres, such as academe. Indeed, Germany's break up after World War II also meant the division of its science system, which soon became very different from each other. In the western part of Germany, several types of institutions were responsible for research, with universities being at the heart of both research and teaching (Meyer-Krahmer, 1990, 37), and in which research was free from the influence of the State (Meyer-Krahmer, 1990, 7). Research in West Germany was also performed in national research centers, as well as research institutes like the Max Planck and Fraunhofer Societies (Meyer-Krahmer, 1990, 34). 
As for the GDR, its scientific community was strongly influenced by the Soviet academic model, and moved away from its German roots (Connelly, 1999, 126). The Socialist Party, which headed the Soviet zone of Germany, played a major role in hiring new faculty members, and allegedly favored higher education to be strongly linked to the East German political elite (Connelly, 1999, 134). The academic environment of East Germany was mainly composed of three types of institutions: universities, mainly focusing on education; the Academy of Sciences, where the vast majority of research was done; and research societies such as Leopoldina, an institution of German tradition that maintained a certain autonomy from the socialist party (Macrakis 1999, 7-8).

In the 1960s, East Germany's Academy of Science officially became socialist. From this moment on, important decisions could not be taken without the approval of party representatives (Nötzoldt 1999, 152). For faculty members, the association with the partyalthough officially optional-was often necessary for advancement to senior positions. (Hohlfeld, 1999, 265). However, despite the party's ties with academe, most of the work done by East German researchers was supposed not to be affected by the ideology advocated by the State (Hohlfeld, 1999, 260). Especially in the natural sciences and engineering disciplines, the quality of East German science was apparently quite high. It is also said that in spite of the numerous influences affecting it, East German science managed to keep a distinct identity: "In the world of science, East German-style communism was [...] a synthesis of a strong German scientific tradition and Soviet ideology, structures, and influence" (Macrakis 1999, 5 and 12).

Germany's 1990 reunification was accompanied by the return to a single German academic system, which was based on that of the West. The eastern system was therefore completely restructured (Sabel 1993, 1754). These important changes affecting former GDR's science certainly had an impact on its researchers, with nearly half of the former East German researchers' careers coming to an early end after the reunification (Sietmann, 1991, 619). Numerous academies have been reformed or even closed after the reunification and a fair number of researchers allegedly lost their position because of ties with the Socialist Unity Party of Germany (SED). Moreover, law apparently forbade hiring professors over the age of 52, meaning that a number of individuals who had lost their position would not be able to find a new one in reunited Germany (Kahn, 1993, 1744-1745). However, scientists who were positively evaluated for their "political and moral standards," as well as for their scientific contribution, were mostly allowed to continue their careers (Sabel, 1993, 1757). It is important to mention that the reduction of academic staff in the former GDR did not solely affect those who were laid off; it had a great impact on networks, hence affecting researchers who were able to keep their position (Hechler \& Pasternack, 2014, 218). In the end, as summarised by Hechler \& Pasternack: "The result of the simultaneous transfer of West German structures and personnel was an integration of East German higher education institutions into the Western academic system without its academics" $(2014,222)$. 
The goal of this paper is to analyse the effects of the reunification on German researchers' scholarly output, with an emphasis on some of the factors associated with the downfall or continuation of East German researchers' careers. More specifically, we aim at answering the following research questions:

1. How did the research activity, publication language, international collaboration and scientific impact of East and West German scholars evolve over the 1980-2000 period?

2. What is the relationship between these factors and the pre- and the post-reunification research activity of GDR individual researchers?

In order to answer these questions, we sampled a number of researchers from both German republics who published during the 1980s and analysed the characteristics of their research output both before and after the reunification, until the year 2000. In light of previous work on the topic, our hypothesis is that East German researchers who were able to keep on publishing after the reunification were 1) most likely working in the scientific and medical disciplines (rather than in the social sciences and humanities), 2) publishing their work in English, and 3) having higher collaborating activities with the West and receiving more citations from these countries.

Previous bibliometric studies on similar topics were conducted during the 1990s, just after the German reunification. Researchers such as Hans-Jürgen Czerwon have studied former East German scientific output on the basis of their institutional affiliations distribution of publication venues $(1995,114)$. Stankus, who also studied the distribution of former East German researchers' publications among journals, showed that, after the reunification, East German researchers started to publish in different journals. Part of the explanation was that some East German journals ceased publication or had merged with similar West German journals to avoid redundancy $(1996,46)$. Czerwon made similar observations, reporting that former East German researchers' papers were scattered in many more journals after the reunification than before $(1995,117)$. Others showed, among other things, that if East German papers were mainly published Eastern journals during the Cold War, soon after the German reunification, former GDR academics "quickly adapted to submit their articles to Western journals" (Grupp, Schmoch \& Hinze, 2001, 370). The originality of this work lies in the fact that we directly studied the scientific output of the same group of researchers over two decades instead of making our analysis based on institutions or journals.

\section{Data and methods}

\section{Identifying active researchers in East and West Germany during the 1980s and their output}

We retrieved all papers (articles, notes and reviews) with institutional addresses in West or East Germany between 1980 and 1989 indexed in the SCI-EXPANDED, SSCI and A\&HCI of Thomson Reuters' Web of Science (WoS). For cases where all institutional addresses were from the same country (East or West Germany), all authors could be assigned to that country. However, in cases of international collaboration, we only included first authors of papers where 
the first address is East or West Germany, as we could only be certain of the link between the first author and the first address. The resulting dataset comprised 171,831 distinct author names (29,837 in the East and 141,994 in the West). To disambiguate these authors (multiple authors may have the same name) and collect all their publications over the 1980-2000 period, we used author data previously disambiguated with the algorithm developed by Caron and van Eck (2014). The algorithm attributes a unique identifier for each author in the WoS database and uses this unique identifier to link articles with their authors. Thus, we retrieved the unique identifier of the 171,831 German authors previously identified, resulting in a final list of 369,569 distinct researchers. Using this identifier, we were able to retrieve all these researchers' publications for the 1980-2000 period, even those who might have moved from or to another country during the studied period. Using the same algorithm, we obtained disambiguated author data for the whole world, which we used as a benchmark to compare the results obtained for East and West Germany.

We then assigned a discipline to researchers based on the journals in which they published most of their articles. Journals were categorized in one of three broad categories, based on the National Science Foundation classification of fields and subfields: Biomedical Research (BM), Natural Sciences and Engineering (NSE) and Social Sciences and Humanities (SSH). In cases where a researcher published an equal number of articles in two disciplines, both disciplines were assigned to the researcher. The final dataset of researchers and publications is described in Table 1. Overall, 371,012 scholars ${ }^{1}$ and 1,198,329 papers are included in the analysis.

Table 1. Number of authors and publications, by field

\begin{tabular}{ccccc}
\hline & \multicolumn{2}{c}{ Authors } & \multicolumn{2}{c}{ Publications } \\
Field & GDR & FRG & GDR & FRG \\
\hline BM & 32,056 & 161,583 & 45,453 & 488,544 \\
NSE & 30,523 & 129,759 & 67,735 & 568,723 \\
SSH & 2,685 & 14,406 & 3,354 & 24,520 \\
Total & 65,264 & 305,748 & 116,542 & $1,081,787$ \\
\hline
\end{tabular}

\section{Language of publication}

In order to analyse the impact of the reunification on the publication language of researchers from the East and the West, we calculated for each researcher and year the percentage of publications in English, German, and another language.

\section{Collaborating and citing countries}

To analyse with which countries East and West Germany researchers collaborated and which countries cited their work, we calculated the proportion of papers written in collaboration with

\footnotetext{
${ }^{1}$ There is a multiplicative effect caused by the assignation of multiple disciplines to some researchers. Thus, the total number of authors in Table 1 is larger than the number of distinct researchers.
} 
both the "Eastern countries" and the "Western countries." We also categorized citations as coming from the West or the East based on the country of affiliation of the first author of the citing paper. We chose to measure citations over a 10-year window so all articles would have the same amount of time to accumulate citations.

\section{Statistical analysis}

We used the Mann-Whitney U test to assess the statistical significance of the impact of the reunification on East German researchers on the characteristics of their research activities. We also used a Kendall's tau-b correlation to determine the relationship between the variation in output from the pre- to the post-reunification period, and the pre-reunification characteristics of individual scientists' research (i.e., the proportion of publications in English, the proportion of articles in collaboration with Soviet satellite states, and with other countries, the proportion of citations received from Western countries). We used the Kendall's tau-b correlation coefficient since the distributions are non-parametric and the relation between the variables is neither clearly linear nor monotonic.

\section{Results}

\section{Evolution of the scientific output}

Figure 1 shows the relative distribution of articles written by the researchers from East and West Germany over the 1980-2000 period included in our dataset. A straight line would indicate that the output of these researchers is stable over time, and the sum of all data points for a given group of scholars equals $100 \%$. We see that for all three fields, the relative output of GDR declines around 1990 and then starts increasing again in the second half of the 1990s. However, the output of FRG was not affected by the reunification, and remained as stable as the world's relative research output during the whole 21-year period.
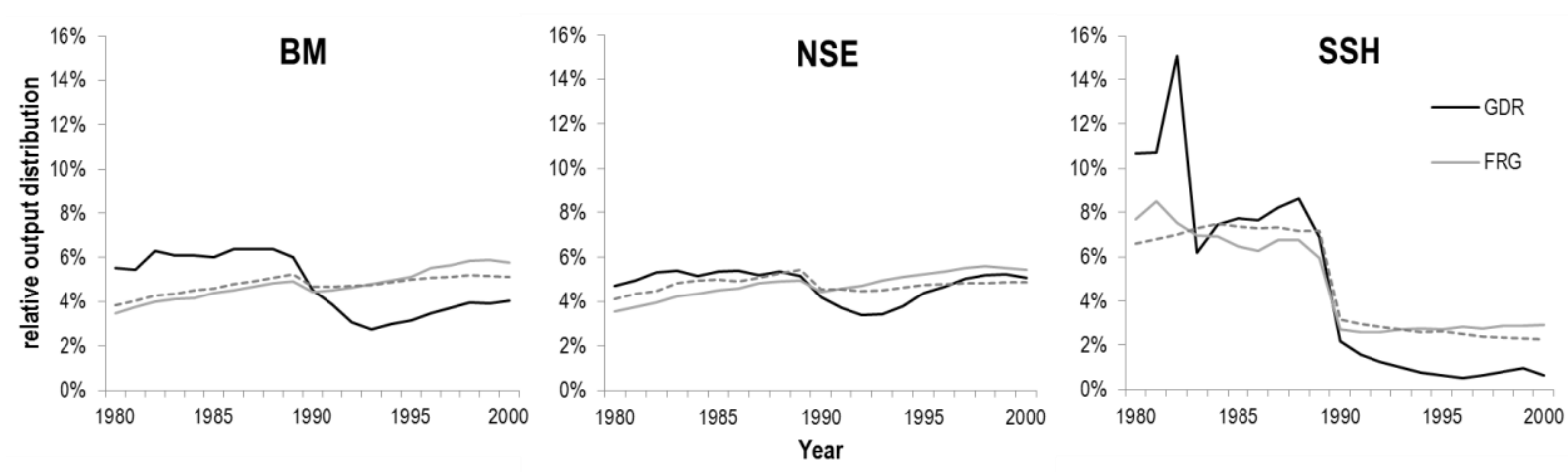

Figure 1. Distribution of the relative research output of the GDR and the FRG researchers over the 1980-2000 period, by field

\footnotetext{
2 "Eastern countries" refers to: Albania, Armenia, Azerbaijan, Bosnia and Herzegovina, Bulgaria, Belarus, China, Croatia, Cuba, Czechoslovakia, Czech Republic, Estonia, German Democratic Republic, Hungary, Kazakhstan, Kyrgyzstan, Latvia, Lithuania, Macedonia, Moldova, Montenegro, Poland, Republic of Georgia, Romania, Russia, Serbia, Serbia and Montenegro, Slovakia, Slovenia, Tajikistan, Turkmenistan, Ukraine, USSR, Uzbekistan, Yugoslavia.

3 "Western countries" refers to: All countries not comprised in the aforementioned definition of Eastern countries.
} 
The sharp decrease in the relative output of the GDR can likely be explained by important changes to the system brought by the reunification which has led scholars to lose positionsand thus stop publishing - and to decrease the activity of those who remained in the system. Indeed, it has been reported that the transformation of the GDR system lasted until 1995 and that the years 1990 to 1992 were the ones during which the former East German scholars have been mostly affected by staff cuts (Hechler \& Pasternack, 2014, 216 and 222), thus affecting the average overall productivity of former East German researchers during this period as observed in Figure 1. As previously stated, the staff reduction process had a great impact on the vast majority of the former GDR academics due to its effect on their networks (Hechler \& Pasternack, 2014, 218). We could speculate that it took a few years for former East German research productivity to be on the rise again.

Our results (Table 2) also show that a larger proportion of researchers from the East than from the West became inactive after the reunification (i.e., no articles were found after 1990). Although, since more than half of the former GDR academics lost their position after the reunification (Hechler \& Pasternack, 2014, 218), we would have expected that, in general, the difference in variation shown in Table 2 would have been greater between GDR and FRG than it actually is with our sample. Since we are studying data on a 21-year-long period, we expected that a large number of researchers identified in the 1980-1989 period would go inactive "naturally." Indeed, we know that in general, the number of publications per researcher is highly skewed, with most researchers having only one publication (Ruiz-Castillo \& Costas, 2014). This is probably what we are seeing for former West German scholars in terms of variation. Indeed, we see that the post-reunification decrease of the number of active researchers in our FRG cohort is much closer to the world benchmark than that of the GDR cohort. We also suspect that a majority of the former East Germans comprised in our sample were part of the group of academics who were most likely able to keep their position after the transition to the western system. The fact that they published in core journals of their discipline indexed in WoS might indicate to some extent that they were more involved into the international research community than their colleagues who did not publish in WoS journals. Therefore, the drop in productivity for the GDR previously shown in Figure 1 might be underestimated, and might not only reflect the reduction of the workforce; it might-maybe even more so-reflect the loss of necessary scholarly networks affecting the remaining former East German academics as well. Nonetheless, the difference between the variations in the number of active researchers from both former republics is still important, especially in BM and NSE.

Table 2. Variation in the number of active researchers in the pre- and post-reunification periods, by field

\begin{tabular}{ccccc}
\hline Field & Group & $1980-1989$ & $1991-2000$ & Variation (\%) \\
\hline \multirow{3}{*}{ BM } & GDR & 32,056 & 2,362 & $-92.6 \%$ \\
& FRG & 161,583 & 20,616 & $-87.2 \%$ \\
& World & $2,667,102$ & 914,709 & $-83.8 \%$ \\
\multirow{2}{*}{ NSE } & GDR & 30,523 & 3,368 & $-89.0 \%$ \\
& FRG & 129,759 & 22,027 & $-83.0 \%$ \\
\hline
\end{tabular}




\begin{tabular}{lcccc}
\hline & World & $2,402,746$ & 416,238 & $-82.7 \%$ \\
& GDR & 2,685 & 102 & $-96.2 \%$ \\
\multirow{2}{*}{ SSH } & FRG & 14,406 & 1,178 & $-91.8 \%$ \\
& World & 758,201 & 74,957 & $-90.1 \%$ \\
\hline
\end{tabular}

\section{Language of publication}

As science was more westernized in the FRG than in the GDR, publishing research in German was a lot more frequent in the GDR than it was in the FRG during the last decade of the cold war, as shown in Figure 2. However, the figure also shows that the anglicization of Eastern science had already started before the end of the cold war and the reunification of the two German states, as the proportion of publications in German was already decreasing both in the GDR and in the FRG. In fact, it has been said that the usage of German as a research language has been declining for at least a century (Grupp, Schmoch \& Hinze, 2001, 379). The results of our research seems to confirm that trend. Nonetheless, it should be noted that after 1990 the proportion of papers published in German by the GDR researchers decreased abruptly, closing the gap between the two reunified states.
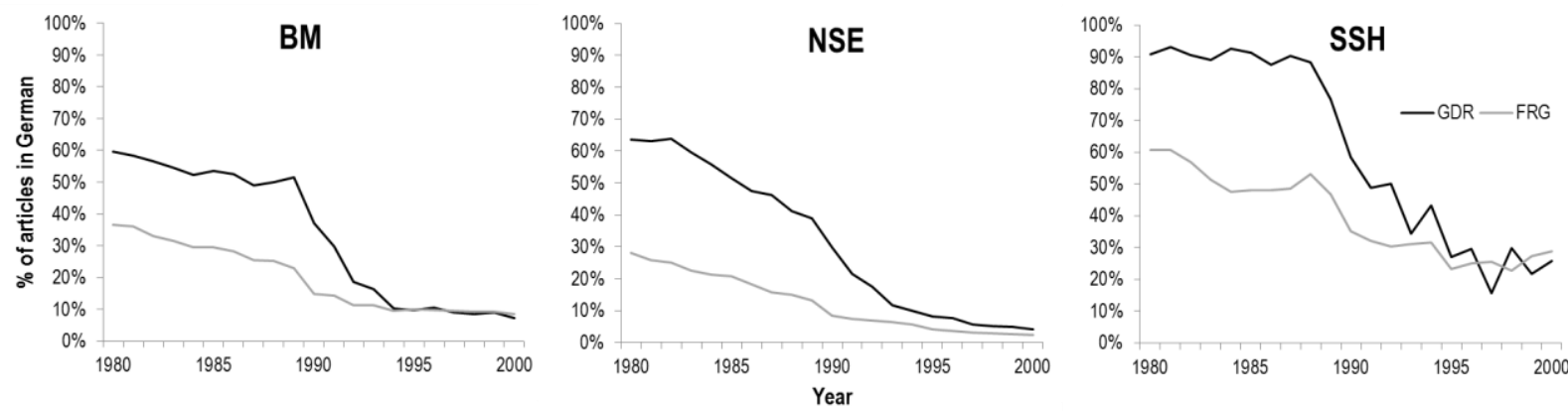

Figure 2. Evolution of the average proportion of publications in German of GDR and FRG researchers over the 1980-2000 period, by field

\section{International collaboration}

Figure 3 shows important differences between the East and West in terms of international collaboration, with international collaboration being more frequent in the West than in the East during the 1980s. We also see that GDR researchers had higher levels of collaboration with Eastern countries than with Western countries, and the FRG researchers' collaboration almost exclusively with Western countries. However, this changed with the reunification, as former GDR researchers' collaboration with the West became a lot more frequent than collaboration with the East. The end of the cold war appears to have also increased collaboration levels between FRG researchers and Eastern countries, especially in NSE. The difference between collaboration with the East and the West may, however, be overestimated by the larger number of papers published by Western countries and the higher coverage of journals in English in the Web of Science (Archambault et al, 2006; Mongeon \& Paul-Hus, 2016). The difference between the pre- and post-reunification periods reflects not only a shift in collaboration practices, but also a higher "survival" rate of GDR researchers who already collaborated with the West before the reunification. On the whole, Figure 3 strongly suggests that the 
reunification of Germany opened up new collaboration channels between the East and the West ${ }^{4}$.
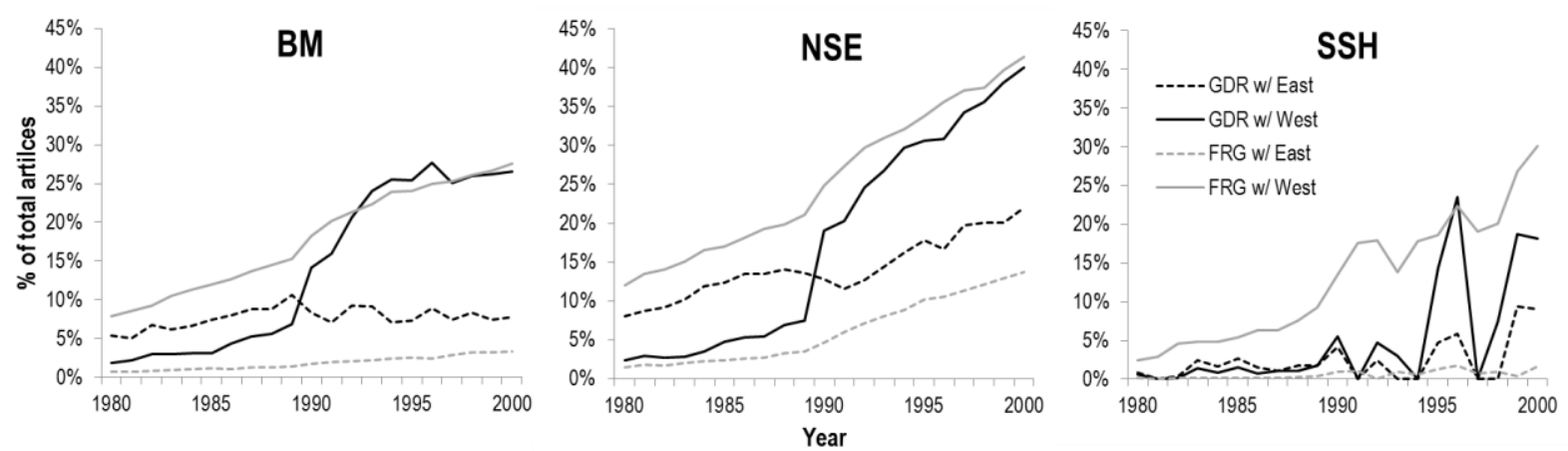

Figure 3. Evolution of the average proportion of publications in collaboration with Eastern and Western countries of GDR and FRG researchers over the 1980-2000 period, by field

\section{Citing countries}

The countries citing the research of both GDR and FRG scholars provide insight on the international visibility of their research. Figure 4 presents the proportion of citations to GDR and FRG articles coming from Eastern countries within a 10-year citation window. We see that in the 1980s, GDR researchers were cited much more by Eastern countries that FRG researchers did. Figure 4 shows that this gap greatly reduced with the reunification and perhaps, more generally, with the fall of the USSR. For both the former GDR and the former FRG researchers, the removal of political barriers created by the war could have brought an increase in citations coming from the "other side." In other words, researchers from the East are increasingly cited by Western countries, and vice versa. East-West Mobility of researchers might also have a slight effect here when, for example, we count self-citations of a researcher from our GDR cohort who moved to a Western country as a citation from the West.
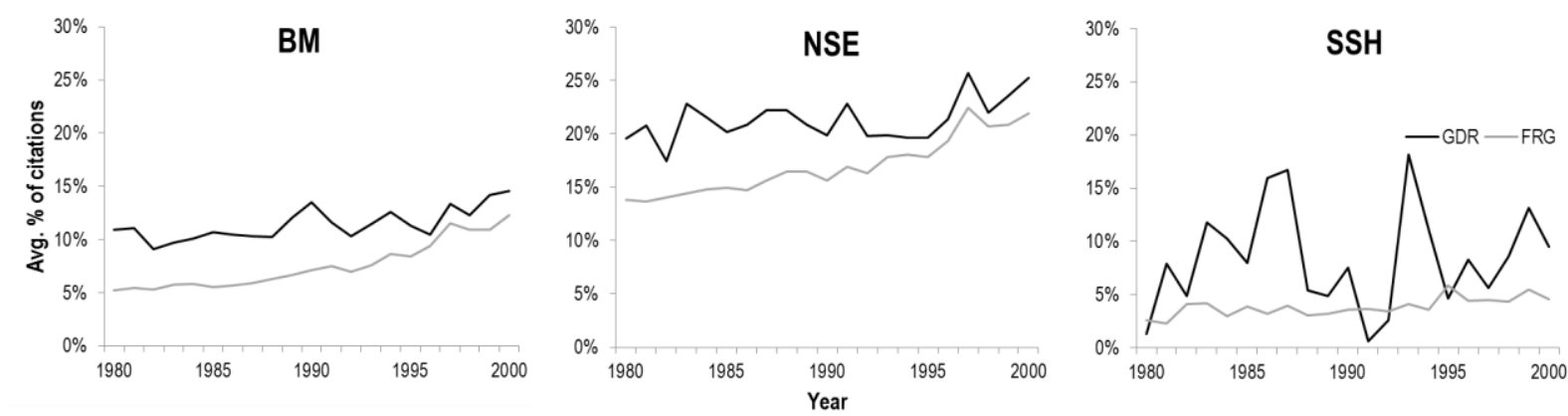

Figure 4. Evolution of the average proportion of citations coming from Eastern countries for GDR and FRG researchers over the 1980-2000 period, by field

\footnotetext{
${ }^{4}$ It should be noted that the East-West mobility of German researchers might slightly inflate their collaboration with EastWest countries. For example, collaborations with the West of a GDR researcher who, himself, moved to the West will be counted as a collaboration between the West and the GDR.
} 


\section{Factors that affect post-reunification output of individual researchers}

To better understand the relationship between the characteristics of individual scholars' research and their career trajectory following the reunification, we compiled how the output of individual researchers increased or decreased, on average, after the reunification. Then, we measured the correlation between these variations in output and the different characteristics of their pre-reunification research output. We calculated the average relative output of each researcher for the pre- and post-reunification period by dividing their output for each period by their total output. Table 3 shows in all fields that the average relative output of individual researchers in the GDR decreased more after the reunification $(-86.8 \%,-73.6 \%$, and $-94.4 \%$, in BM, NSE and SSH respectively), than in the FRG, where the average decrease was $61.0 \%$, $57.3 \%$ and $82.9 \%$ in BM, NSE and SSH respectively. We performed a Mann-Whitney U test to determine if the differences in average relative output variation between the GDR and the FRG cohorts were statistically significant. The results of the Mann-Whitney U test are displayed in Table 3 and show that the observed differences in all field were statistically different.

Table 3. Difference between the pre- and post-reunification relative output of individual researchers

\begin{tabular}{llccccc}
\hline \multirow{2}{*}{ Field } & \multirow{2}{*}{ Group } & $\begin{array}{c}\text { Average relative output } \\
\text { variation }\end{array}$ & Mean rank & $\mathrm{U}$ & $\mathrm{z}$ & $\mathrm{p}$ \\
\hline \multirow{2}{*}{ BM } & GDR & $-86.8 \%$ & $92,273.87$ & $2,444,121,715$ & -28.382 & .000 \\
& FRG & $-61.0 \%$ & $97,721.89$ & & & \\
\multirow{2}{*}{ NSE } & GDR & $-73.6 \%$ & $76,168.45$ & $1,859,047,457$ & -26.232 & .000 \\
& FRG & $-57.3 \%$ & $81,076.08$ & & & \\
\multirow{2}{*}{ SSH } & GDR & $-94.4 \%$ & $8,225.47$ & $18,479,428$ & -8.034 & .000 \\
& FRG & $-82.9 \%$ & $8,605.74$ & & \\
\hline
\end{tabular}

We then tried to identify some of the factors that might have had an effect on German researchers post-reunification output. Table 4 shows the correlation coefficients obtained with the Kendall's tau-b test. Overall, we observe small but significant correlation between all the factors tested and the output of researchers. Articles in English and citations from Western countries appear to have a stronger positive effect for GDR researchers than for FRG researchers, while international collaboration with the Western countries correlates more strongly with the research output for FRG researchers. The output variation for SSH researchers, both in the GDR and the FRG, correlates more strongly with the proportion of publications in collaboration with the West (.206 and .256, respectively) than with the East (.057 and .053, respectively).

Table 4. Correlation between characteristics of the pre-reunification output of individual researchers and the variation in their relative output.

\begin{tabular}{cccccc}
\hline \multirow{2}{*}{ Field } & Group & $\begin{array}{c}\text { \% of articles in } \\
\text { English }\end{array}$ & $\begin{array}{c}\text { \% of art co-authored } \\
\text { with the East }\end{array}$ & $\begin{array}{c}\text { \% of art co-authored } \\
\text { with the West }\end{array}$ & $\begin{array}{c}\text { \% of citations } \\
\text { from the West }\end{array}$ \\
\hline \multirow{2}{*}{ BM } & GDR & .241 & .332 & .311 & .205 \\
& FRG & .196 & .178 & .437 & -.009 \\
\hline
\end{tabular}




\begin{tabular}{clllll}
\hline \multirow{2}{*}{ NSE } & GDR & .230 & .198 & .159 & .232 \\
& FRG & .164 & .264 & .420 & .047 \\
\multirow{2}{*}{ SSH } & GDR & .186 & .057 & .206 & .273 \\
& FRG & .111 & .053 & .256 & .157 \\
\hline
\end{tabular}

Note: all correlations are statistically significant at $\mathrm{P}<.01$

\section{Discussion and conclusion}

Our results highlight important differences in the research activity of East and West German researchers during the 1980s, and show that the reunification seems to have reduced these differences, as collaboration and communication channels reopened and researchers from the GDR increased their proportion of English papers. The different scientific systems and sociopolitical contexts of the GDR and the FRG, and the changes brought by the reunification, both had an undeniable effect on the trends observed.

However, some of these differences might be, at least in part, due to the characteristics of the data source we used. For instance, fewer East German researchers are comprised in our dataset than West Germans researchers, which is mainly a consequence of the lower coverage of GDR research by the Web of Science. Indeed, during the Cold War, East German researchers reportedly published in national journals (Grupp \& Hinze, 1994, 97) and thus, their output was less likely to be indexed by this database (Grupp, Schmoch \& Hinze, 2001, 378). It has also been reported that East German researchers rarely had the opportunity to publish in international journals (Warlimont, 1995, 259), and that State authorization was mandatory to do so (Hohlfeld, 1999, 262-263). Conversely, because of their ties with the Americans, West Germans published a larger proportion of their work within U.S. and Western journals (Stankus, 1996, 43), indexed in WoS, which might explain the greater number of former FRG authors in our sample.

Data on SSH publications were very limited in our dataset, especially for the former GDR. This could in part be explained by the fact that WoS has a weaker coverage of journals from those disciplines, especially those coming from non-English-speaking countries (Mongeon \& PaulHus, 2016). The idea that GDR's main research focus was natural sciences and engineering might also explain the smaller number of publications found in SSH (Macrakis, 1999, 8; Sabel, 1993, 1756). Despite this smaller coverage, we decided to include SSH publications data into our study, as previous analyses of German reunification omitted these disciplines. For instance, Grupp, Schmoch and Hinze (2001) stated that it would be interesting to study effects of the German scientific reunification on the SSH field. Moreover, confidence in our decision to include SSH data in this study is reinforced by the fact that the effects observed were statistically significant. Nonetheless, further bibliometric studies of SSH in the GDR could benefit from the inclusion of other sources and types of publication data such as books, as they were at the time (and, to some extent, still today) the main means of knowledge diffusion in Arts and Humanities. 
On the whole, our analysis provides empirical evidence that the reunification of Germany had important consequences for the careers of East German researchers, especially in fields that have stronger ties with the social and political context (i.e., SSH mostly, but also BM). While consequences were also apparent for researchers in NSE, these were less important, as these fields generally produce knowledge that is international in scope and, thus, less affected by the political context. The results of our study also support the hypothesis that when the East German system was westernized by the reunification: researchers who already had direct ties with the West (e.g., scientific collaboration), but also indirect ties (e.g., publications in English, citations from researchers in the West) were better equipped to survive this transition than their colleagues who did not have such ties with the West.

\section{Acknowledgements}

The authors would like to thank the two anonymous referees for their precise and constructive comments, as well as Rodrigo Costas from the Centre for Science and Technology Studies (CWTS) for his help with the disambiguation of the Web of Science authors.

\section{References}

Archambault, É., Vignola-Gagné, É., Côté, G., Larivière, V. \& Gingras, Y. (2006). Benchmarking scientific output in the social sciences and humanities: The limits of existing databases, Scientometrics, 68(3): 329-342.

Caron, E. \& van Eck, N. J. (2014). Large scale author name disambiguation using rule-based scoring and clustering. In E. Noyons (Ed.), Proceedings of the 19th International Conference on Science and Technology Indicators. (p. 79-86). Leiden: CWTS-Leiden University Leiden.

Connelly, J. (1999). The foundations of diversity: communist higher education policies in Eastern Europe, 1945-1955. In K. Macrakis \& D. Hoffmann (Ed.), Science under socialism, East Germany in comparative perspective (p. 125-139), Cambridge, MA : Harvard University Press.

Czerwon, H.-J. (1995). The research landscape in East Germany after the reunification - A bibliometric analysis. In M. E. D. Koenig \& A. Bookstein (Ed.), Proceedings of the Fifth Biennial Conference of the International Society for Scientometrics and Informetrics (p. 113-117). Medford, NJ : Learned Information.

Grupp, H. \& Hinze, S. (1994). International orientation, efficiency of and regard for research in East and West Germany: a bibliometric investigation of aspects of technology genesis in the united Germany. Scientometrics, 29(1), 83-113.

Grupp, H., Schmoch, U. \& Hinze, S. (2001). International alignment and scientific regard as macro-indicators for international comparisons of publications. Scientometrics, 51(2), 359-380. 
Hechler, D. \& Pasternack, P. (2014). From transformation to transfer: the transformation of the East German academic system 1989/90-1995. Revue d'études comparatives EstOuest, 45(1), 207-227.

Hohlfeld, R. (1999). Between autonomy and state control: genetic and biomedical research. In K. Macrakis \& D. Hoffmann (Ed.), Science under socialism, East Germany in comparative perspective (p. 247-265), Cambridge, MA : Harvard University Press.

Kahn, P. (1993). Reunification: scientists in the East count the costs. Science, 260(5115), 1744-1746.

Macrakis, K. (1999). Introduction: interpreting East German science. In K. Macrakis \& D. Hoffmann (Ed.), Science under socialism, East Germany in comparative perspective (p. 1-22), Cambridge, MA : Harvard University Press.

Meyer-Krahmer, F. (1990). Science and technology in the Federal Republic of Germany. Harlow, Royaume-Uni : Longman.

Mongeon, P. \& Paul-Hus, A. (2016). The journal coverage of Web of Science and Scopus: a comparative analysis. Scientometrics, 106(1), 213-228.

Nötzoldt, P. (1999). From German Academy of Science to Socialist Research Academy. In K. Macrakis \& D. Hoffmann (Ed.), Science under socialism, East Germany in comparative perspective (p. 140-157), Cambridge, MA : Harvard University Press.

Ruiz-Castillo, J., \& Costas, R. (2014). The skewness of scientific productivity. Journal of Informetrics, 8(4), 917-934.

Sabel, B. A. (1993). Science reunification in Germany: a crash program. Science, 260(5115), 1753-1758.

Sietmann, R. (1991). Reunification blues for East German scientists. Science, 253(5020), 619.

Stankus, T. (1996). The journals of German university and engineering school scientists before and after national reunification. Science \& Technology Libraries, 16(1), 35-47.

Warlimont, H. (1995). Reorganizing a major materials research institute in East Germany IFW Dresden. Advanced Materials, 7(3), 259-262. 